DOI: $10.38136 /$ jgon.716118

\title{
Postmenopozal Uterin Kanamalı Hastaların Değerlendirilmesi
}

\section{Evaluation of Women with Postmenopausal Uterine Bleeding}

\author{
Z.Aslı OSKOVI-KAPLAN \\ Özlem EVLIYAOĞLU ${ }^{2}$ \\ Salim ERKAYA \\ Hasan Onur TOPÇU ${ }^{4}$
}

(1) Orcid ID:0000-0001-7554-4393

(1) Orcid ID:0000-0002-4583-6616

(1) Orcid ID:0000-0002-0215-8552

(1) Orcid ID:0000-0003-1877-7240

\section{${ }^{1}$ Ankara Șehir Hastanesi Kadın Hastalıkları ve Doğum Kliniği \\ ${ }^{2}$ Gülhane Eğitim ve Araștırma Hastanesi Kadın Hastalıkları ve Doğum Kliniği \\ ${ }^{3}$ Etlik Zübeyde Hanım Kadın Hastalıkları ve Doğum Hastanesi Kadın Hastalıkları ve Doğum Kliniği \\ ${ }^{4}$ Memorial Ankara Hastanesi Kadın Hastalıkları ve Doğum Kliniği}

\section{Öz}

Amaç: Postmenopozal uterin kanama (PUK) ile başvuran hastalarda ultrasonografik bulguların ve patoloji sonuçlarının değerlendirlmesi.

Materyal ve Metot: Bu tanımlayıcı retrospektif çalışma, Ekim 2008- Mayıs 2015 arası, Zekai Tahir Burak Kadın Sağlığı Eğitim ve Araştırma Hastanesine PUK nedeniyle başvuran toplam 979 kadının sosyodemografik ve klinik bilgileri, medikal kayıtlardan elde edilerek yapılmıştır. Hastaların yaş, gravida, parite, endometrial kalınlıkları ve endometriumun histopatoloji sonuçları incelenmiştir.

Bulgular: PUK nedeniyle başvuran hastaların yaşlarının ortanca değeri 55 (42-88) idi. Gravida ve parite ortanca değerleri sırasıyla 5 (0-22), 3 (0-15) idi. Transvajinal ultrasonografide saptanan ortalama endometrial kalınlık ise $7.3 \pm 6.5 \mathrm{~mm}$ idi. PUK patoloji sonuçları sırası ile atrofi ve yetersiz endometrium \%33.5; yüzeyel epitel, proliferatif veya sekretuar endometrium \% 28.2 ve endometrial polip \%26.6 oranda izlemekteydi. Hastaların \% 4.3 'ünde endometrium kanseri tespit edildi, servikal patolojiler ise \% 2.8 oranında gözlendi.

Sonuç: PUK çoğunlukla benign endometrial patolojiler ile birliktelik göstermektedir, ancak PUK nedeniyle başvuran her 20-25 kadından 1'inde endometrium kanseri tespit edilmektedir.

Anahtar Kelimeler: postmenopozal uterin kanama, endometrium kanseri, atrofik endometrium, endometrial polip

\section{Gíriş}

Postmenapozal uterin kanama (PUK), jinekoloji pratiğinde sık karşılaşılan konulardan biridir ve menapozun hemen sonrasında yaklaşık \% 10 oranda görülmektedir (1). PUK şikayeti ile başvuran hastaların yaklaşık \%10'unda endometrium kanseri saptanırken, benign jinekolojik patolojiler de $20-40 \%$ oranında görülebilmektedir (1-3). Bununla birlikte, vajinal kanama endometrium kanserlerinin en sık bulgusudur ve hastaların \%95inde PUK görülmektedir (4). PUK yönetim ve takibinde en sık kullanılan yöntemler ultrasonografi,

\section{ABSTRACT}

Aim: To investigate the etiologic factors of Postmenopausal Uterine Bleeding (PUB).

Material and Methods: This descriptive retrospective study analyzed the records of women who attended to hospital with complaints of PUB between October 2008 and May 2015. A total of 979 women were recruited. Age, gravidity, parity, endometrial thickness and the histopathology of endometrium were evaluated.

Results: The median age of the patients was 55 (42-88), gravidity was 5 $(0-22)$ and parity was $3(0-15)$. The mean thickness of the endometrium was $7.3 \pm 6.5 \mathrm{~mm}$ in transvaginal ultrasound. The atrophic and insufficient endometrium were the most frequently seen histopathologic findings with $33.5 \%$. Surface epithelium, proliferative or secretory endometrium were found $28.2 \%$ of patients. Endometrial polyps were seen 26.6 $\%$ of the cases. And endometrium cancer was found to be $4.3 \%$ and cervical pathologies were found to be $2.8 \%$ of the cases.

Conclusion: PUB was associated with benign conditions; however it must be kept in mind that 1/20-25 woman should be diagnosed with endometrial cancer.

Keywords: postmenopausal uterine bleeding, endometrial cancer, atrophic endometrium, vaginal bleeding

endometrial biyopsi ve histeroskopidir. Ayırıcı tanıda her zaman endometrium kanseri yer alması gerektiğinden endometrial örnekleme yapılması PUK vakalarında önem arz etmektedir. Transvajinal ultrasonografide endometrial kalınlığın $<5$ mm olması, endometrial kanser riskini çoğunlukla dışlamaktadır (5). Geçmiş yıllarda endometrial örnekleme amacı ile dilatasyon ve küretaj (D\&C) tercih edilirken 1980'lerden sonra tek kullanımlık biyopsi kanülleri, orijinal marka adı ile Pipelle kanülleri kullanıma girmiş ve uygulamayı kolaylaştırmıştı. 
Kör endometrial örnekleme yöntemlerinin doku örneklemesi için birinci basamak yöntem olmakla birlikte, bu testlerin yalancı negatiflik oranının da yüksek olduğu göz önünde bulundurulmalıdır (6). Yabancı kaynaklarda PUK'un etiyolojisinde de birçok faktör suçlanmaktadır. Bunlar \% 60-80 oranla endometrial atrofi, \% 15-25 oran ile ekzojen östrojen tedavisi, \% 2-12 oran ile endometrial polip, $\% 5-10$ oran ile endometrial hiperplazi ve $\% 10-15$ oran ile endometrial kanserdir (7). Ülkemizde klinik pratikte ekzojen östrojen kullanımı gibi bazı faktörlerin yabancı ülkelerle kıyaslandığında farklı olma intimali bulunmaktadır. Bu yüzden çalışmamızda hastanemize PUK nedeniyle başvuran hastaların kanama nedenlerinin endometrial patoloji sonuçlarına göre sunulması hedeflenmiştir.

\section{GEREÇ VE YÖNTEM}

Bu tanımlayıcı retrospektif çalışma, Ekim 2008- Mayıs 2015 arası, Zekai Tahir Burak Kadın Sağlığı Eğitim ve Araştırma Hastanesine PUK nedeniyle başvuran toplam 979 kadının sosyodemografik bilgileri ve medikal kayıtları incelenerek yapılmıştır. Çalışma için hastanenin eğitim ve planlama kurulundan 29/04/2015 \#19 numarası ile onay alınmıştır. Çalışmaya ofis ortamında lokal anestezi altında gerçekleştirilen endometrial örnekleme sonuçları dahil edilmiştir. Hastaların yaş, gravida, parite, transvajinal ultrasonografide endometrial kalınlıkları ve PUK nedenleri incelenmiştir.

Veriler Windows için SPSS 22 (Statistical Package for the Social Sciences, SPSS Inc., Chicago, IL) programında analiz edilmiştir. Demografik veriler için ortalama ve ortanca değerler kullanılmıştır, patoloji sonuçları için ise yüzdeler kullanılmıştır.

\section{BULGULAR}

PUK nedeniyle endometrial örnekleme yapılan 979 hastanın yaşlarının ortanca değeri 55 (42-88) idi. Gravida ortanca değeri 5 (0-22), parite ortanca değeri 3 (0-15) idi (Tablo 1). Transvajinal ultrasonografide saptanan ortalama endometrial kalınlık $7.3 \pm 6.5 \mathrm{~mm}$ idi.

Tablo 1. Postmenopozal kanaması olan hastaların sosyodemografik özellikleri

\begin{tabular}{|l|c|}
\hline Değişkenler & Hasta yüzdesi $(\mathrm{n}=979)$ \\
\hline Yaş (yıl) & $55(42-88)$ \\
\hline Gravida & $5(0-22)$ \\
\hline Parite & $3(0-15)$ \\
\hline Endometrial kalınlık $(\mathrm{mm})$ & $7.3 \pm 6.5$ \\
\hline
\end{tabular}

PUK nedenleri incelendiğinde atrofi ve yetersiz endometrium \% 33.5 ile ilk sırada yer almaktaydı. Bunu \% 28.2 ile yüzeyel epitel, proliferatif veya sekretuar endometrium ve \% 26.6 ile endometrial polip izlemekteydi. Hastaların \% 4.3 'ünde endometrium kanseri tespit edildi. Servikal patolojiler ise \% 2.8 oranında gözlendi (Tablo2).

Tablo 2. Postmenopozal Kanama Nedenleri ve Literatür ile Kıyaslanması

\begin{tabular}{|l|c|c|}
\hline Postmenopozal Kanama Nedenleri & Hasta yüzdesi (n= 979) & $*((7))$ \\
\hline${ }^{1}$ Endometrium kanseri, (\%) & $\mathbf{4 . 3} \%$ & $\mathbf{1 0 - 1 5} \%$ \\
\hline Endometrial polip, (\%) & $\mathbf{2 6 . 6 \%}$ & $\mathbf{2 - 1 2} \%$ \\
\hline Atrofi, yetersiz endometrium, (\%) & $\mathbf{3 3 . 5} \%$ & $\mathbf{6 0 - 8 0} \%$ \\
\hline${ }^{2}$ Servikal patoloji, (\%) & $\mathbf{2 . 8} \%$ & \\
\hline Endometrial hiperplazi, (\%) & $2.0 \%$ & $5-10 \%$ \\
\hline Ekzojen estrojen, (\%) & $0.7 \%$ & $15-25 \%$ \\
\hline $\begin{array}{l}\text { Yüzeyel epitel + proliferatif veya } \\
\text { sekretuar endometrium, (\%) }\end{array}$ & $\mathbf{2 8 . 2 \%}$ & \\
\hline${ }^{3}$ Diğer, (\%) & $1.9 \%$ & \\
\hline
\end{tabular}

${ }^{1}$ : Adenokanser + karsinosarkom + malign mikst müllerian tümör

2: Servikal polip + servisit + servikal kanser

3: Myom,granüloza hücreli tümör, tuba kanseri, granülomatoz endometrit

*: Referans ${ }^{2}$
Endometrium kanserleri adenokanserler, karsinosarkomlar ve malign mikst müllerian tümörler oluşturuyordu. Servikal patolojileri ise servikal polip, servisit ve servikal kanserler oluşturuyordu. Ayrıca myom, granüloza hücreli tümör, tuba kanseri, granülomatoz endometrit saptanan hastaların oranı \%1.9 idi.

Toplamda 40 hastada endometrioid adenokanser mevcuttu. Hastalardaki ortalama endometrium kalınlığı $15.5 \pm 11.3 \mathrm{~mm}$ idi, 2 hastada transvajinal ultraonografi endometrial kalınlık ölçümü $1 \mathrm{~mm}$ idi

\section{TARTIŞMA VE SONUÇ}

Çalışmamızda PUK nedeniyle hastanemize başvuran hastaların \% 4.3 ünde endometrial kanser saptanırken, ekzojen östrojen kullanımına bağı PUK oranı sadece \% 0.7 idi. PUK nedeni ile hasta değerlendirilirken göz önünde bulundurulan ayırıcı tanılar genellikle yabancı kaynaklara göre yapılmaktadır. Ancak çalışmamızda da gösterildiği gibi ekzojen östrojen kullanımına bağlı PUK, hastanemize başvuran hastalarda \% 0.7 iken, kadın doğum hekimlerinin temel kitaplarından sayılan kitaplarda bu oran \%15-25 oranında verilmektedir (7).

Türkiye'de yapılan ve çalışma amacının PUK'lı hastalarda transvajinal ultrasonografi ile ölçülen endometrial kalınlık ile endometrial patoloji arasındaki ilişkiyi araştırmak olan bir çalışmada \%18.6 oranında atrofik endometrium, \% 8.9 oranında yetersiz materyal, $\% 14.4$ oranında proliferatif endometrium, $\%$ 3.7 oranında sekretuar endometrium, $\% 25.4$ oranında endometrial hücreler, \% 5.4 oranında endometrial hiperplazi, \% 14.3 oranında endometrial polip, \% 9.3 oranında endometrial kanser saptanmıştır (8). Çalışmamızda atrofik endometrium ve endometrial polip oranlarını sırasıyla \% 33.5 ve $\% 26.6$ ile yukarıdaki çalışmaya göre daha yüksek oranda bulunmuştur.

Postmenapozal dönemde transvajinal ultrasonografinin temel amacı endometrium kanserini dışlamaktır. Endometrial kalınlık için $5 \mathrm{~mm}$ eşik değeri alındığında endometrium kanserini tanımak için sensitivitesi \% 96, spesifitesi $\% 61$ olarak bildirilmiştir; ve endometrium kalınlığu $\leq 5 \mathrm{~mm}$ olan PMK hastalarında konservatif tedavi önerilmiştir. (1). Bununla birlikte en yüksek sensitivitesi olan eşik değer $3 \mathrm{~mm}$ olup, maliyet-etkinliğine yönelik bir çalışma yoktur (1). Bizim çalışmamızda endometrium adenokanseri tanısı alan 40 hastadan 2'sinde endometrial kalınlık $1 \mathrm{~mm}$ olarak raporlanmıştır.

Postmenapozal kanamalı hastaların değerlendirilmesinde endometrial örneklme, transvajinal ultrasonografi, salin infüzyon sonografisi ve histeroskopi kullanılabilir $(5,9)$. Toplam 979 hastalık serimizde, yaklaşık her 3 hastadan birinde atrofi kanaması görülmekte ve 4 hastadan birinde endometrial polip gibi yapısal bir sorun bulunmaktadır. Başka bir çalışmada asemptomatik endometrium kalınlaşması olan hastaların \%1'inde ve endometrial polipektomi yapılan hastaların 2.7\%'sinde atipi veya kanser gözlenmiştir (10). Yurtdışı kaynaklarda \% 10, bizim çalışmamızda \% 4.3 olarak bulunan malignite oranları göz önünde bulundurulduğunda, PUK semptomu olan hastalara ileri inceleme yapılması gereklmektedir.

Ülkemizdeki PUK nedenleri ile yabancı ülkelerdeki PUK nedenleri farklıık göstermektedir. Bu yüzden ülkemizde PUK nedeni ile başvuran hastaların bilgilerinin birleştirildiği ve sunulduğu daha büyük hasta gruplu ve tüm Türkiye yi temsil edecek ulusal çalışmalara intiyaç vardır.

Finansal Kaynak: Bu çalışma için herhangi bir yerden finansal kaynak alınmamıştır.

Çıkar Çatışması: Yazarlar herhangi bir çıkar çatışmaları olmadığını ilan ederler. 


\section{REFERANSLAR}

1.van Hanegem N, Breijer MC, Khan KS, Clark TJ, Burger MP, Mol BW, et al. Diagnostic evaluation of the endometrium in postmenopausal bleeding: an evidence-based approach. Maturitas. 2011;68(2):155-64.

2.Dijkhuizen FP, Brolmann HA, Potters AE, Bongers MY, Heinz AP. The accuracy of transvaginal ultrasonography in the diagnosis of endometrial abnormalities. Obstet Gynecol. 1996;87(3):345-9.

3.Epstein E, Ramirez A, Skoog L, Valentin L. Dilatation and curettage fails to detect most focal lesions in the uterine cavity in women with postmenopausal bleeding. Acta obstetricia et gynecologica Scandinavica. 2001;80(12):1131-6.

4.Brenner PF. Differential diagnosis of abnormal uterine bleeding. American journal of obstetrics and gynecology. 1996;175(3 Pt 2):766-9.

5.Goldstein SR. Appropriate evaluation of postmenopausal bleeding. Menopause. 2018;25(12):1476-8.
6.Obstetricians ACo, Gynecologists. Diagnosis of abnormal uterine bleeding in reproductive-aged women. Practice bulletin. 2012(128):197-206.

7.Dowdy SC, Mariani A, Lurain JR: Uterine cancer. In Berek \& Novak's Gynecology. 15th ed. Wolters Kluwer \& Lippincott Williams \& Wilkins 2012; 35:1250-1303.

8.Selçuk S, Asoglu M.R., Çelik C, Tuğ N,Çam Ç, Karateke A. Postmenopozal Vajinal Kanamalı Hastalarda Endometrial Kalınlıkla Histopatoloji Sonuçları Arasındaki ilişki. Zeynep Kamil Tıp Bülteni, Cilt: 42 Yıl : 2011 Sayı: 1.

9.Famuyide AO, Breitkopf DM, Hopkins MR, Laughlin-Tommaso SK. Asymptomatic thickened endometrium in postmenopausal women: malignancy risk. J Minim Invasive Gynecol. 2014;21(5):782-6.

10.Goldstein SR, Lumsden MA. Abnormal uterine bleeding in perimenopause. Climacteric. 2017;20(5):414-20. 